\title{
Hepatitis B Vaccination Status among Medical Students at King Faisal University
}

\author{
Doaa Ali Aish Alsultan ${ }^{1}$, Kholood Abdullatif Mohamed Ahmed ${ }^{1}$, Fadak Yousef Hassan Alhashem ${ }^{1}$, \\ Fatimah Abdullah Alhijab $^{1}$, Munirah yousef Buaeshah ${ }^{1}$, Sayed Ibrahim Ali ${ }^{2}$, Naglaa Ali Hassan Sidiq ${ }^{2}$

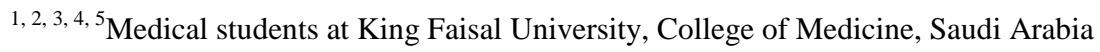 \\ ${ }^{6,7}$ King Faisal University, College of Medicine, Saudi Arabia
}

\begin{abstract}
Background: Hepatitis B virus (HBV) infection causes significant morbidity and mortality worldwide. Occupational exposure of health care workers and medical students increases their risk of acquiring $\mathrm{HBV}$ infection and many authorities recommend vaccination. However, significant number of them doesn't receive $H B V$ immunization, and remains at an increased risk to the infection. Objective: To determine the hepatitis B vaccination status among Medical students at King Faisal University (KFU) and define associated risk factors and possible causes. Result: One hundred and ninety seven medical students at KFU completed selfadministered questionnaires which included questions about demographic characteristics, HBV vaccination status, knowledge of hepatitis $B$ vaccine and reasons for not receiving the vaccine. One hundred and seventeen (59.4\%) had received at least one dose of hepatitis $B$ vaccine while $23(11.7 \%)$ had never received the vaccine, and 57 (28.9\%) of the students are not sure that they receive the vaccine. About $156(79.2 \%)$ participants received the hepatitis $B$ vaccine after entering the college of medicine, 28 (14.7\%) did not. Only $67(43.2 \%)$ of those who received the vaccine, took the complete doses and 88(56.8\%) received only 1 or 2 doses. First year medical students were less vaccinated than third year medical students $(p<0,001)$. Conclusion: The hepatitis $B$ vaccination status among medical students at KFU is low. National and institutional legislation for adult vaccination against Hepatitis $B$ should be promulgated for those at higher risk.
\end{abstract}

Keywords: Hepatitis B Virus, Hepatitis B Vaccine, immunization status, medical student at KFU

\section{Introduction}

Hepatitis B is an infectious disease of the liver caused by hepatitis $\mathrm{B}$ virus (HBV) which is a partially double-stranded virus that belongs to hepadnaviruses family (1). The virus is carried by the bloodstream to the liver, and it can only replicate there (1-2). The HBV infection may manifest as asymptomatic infection, self-limited acute hepatitis, or fulminant hepatitis that require liver transplantation (1-2). About $5-10 \%$ of people who are infected with HBV may develop the chronic form of the disease (1). Chronic HBV infection may lead to serious complications such as cirrhosis, liver failure or primary hepatocellular carcinoma (HCC) (12). Also of note, hepatitis $B$ virus has been linked to membranous glomerulonephritis (3). Chronically infected HBV patients have a $15-25 \%$ risk of dying early due to HBV-related cirrhosis and HCC (4). HBV have inverse association with age. $25 \%$ of infants and children who have been infected with HBV develop HBV-related HCC or cirrhosis (2).

Hepatitis B is a serious public problem. It affects more than 2 billon people worldwide (1-5). More than 350 million of the infected people are chronic carriers (1-6). Annually, there are 0.5 to 1.2 million people die from hepatitis B infection (7). HBV infection has high endemicity in developing countries, such as South East Asia, China, sub-Saharan Africa and the Amazon Basin $(5,9)$. At such areas at least $8 \%$ of populations are chronic HBV carriers $(5,8)$. In 2007, about 9000 new cases of viral hepatitis were diagnosed in the Kingdom of Saudi Arabia (KSA) $(6,9)$. At that time viral hepatitis infection was the second most common infectious disease in KSA $(8,9)$. In KSA significant mortality and morbidity is caused by the viral hepatitis infection which puts a great burden in the health care system, since hepatitis B treatment is expensive and might associate with drug resistance and adverse effects $(9,10)$. KSA is considered an area of high endemicity since the prevalence of hepatitis B surface antigen (HBsAg) ranges from 7.4 to $17 \%(11)$.

HBV is transmitted when an infected blood or body fluid come into contact with mucosal or percutaneous tissue (2). HBV can be transmitted sexually, from mother to child, from healthcare providers to patients or vice versa (1-2). Patientto-provider transmission is an important source of new HBV infection worldwide, with risk of $6-30 \%(2,12)$. The incidence of needle stick injury induced HBV infection is high among medical students as they are learning to do procedures and less cautious than other health workers (1415). In the medical college of Nigerian university $48 \%$ of the students exposed to needle stick injuries (15). Medical students are at risk of acquiring HBV infection when exposed to clinical cases. In KSA the prevalence of hepatitis B and C in health care collages for males and females is 0.17 and $0.78 \%$ respectively in the $18-21$-year-old, and 0.39 and 0.90 in 22-30-year-olds students (17).

Primary prevention by immunization with HBV vaccines remains the most effective means of controlling HBV infection, which is safe, too (18). In KSA, the immunization program against HBV was introduced in 1989 , since then the prevalence of $\mathrm{HBV}$ infection reduced from $7 \%$ to $0.3 \%$ in 1997(11). Hepatitis B immunization strategies include routine infant vaccination (the primary immunization), prevention of prenatal HBV transmission and catch-up vaccination of older age groups (18). HBV vaccine demand becomes higher due to the cost effectiveness of $\mathrm{HBV}$ treatment (19). The efficacy of HBV vaccine diminished with increasing age (20). A study in King Adbulaziz University in 


\section{International Journal of Science and Research (IJSR) \\ ISSN (Online): 2319-7064}

Index Copernicus Value (2013): 6.14 | Impact Factor (2015): 6.391

Jeddah showed the Anti-HBs to be significantly low after 1424 years of primarily immunization of medical students (19).

Medical students are considered to be a high risk group of HBV infection as they could readily come in contact with infected body fluids from patients and hospital equipments during their clinical practice. The present study was conducted among medical students in KFU in Al-Ahsa, targeting their HBV vaccination status. The aim was to estimate the number of medical students covered by hepatitis $B$ vaccination and define associated risk factors and possible causes for uncovered.

\section{Methods}

Across-sectional study was conducted on March 2015, using a questionnaire survey which was administered to 450 medical students at KFU in Al-Ahsa. The study targeted the first, second and third year students. Students were interviewed using a structured self-completed questionnaire which consisted of 20 questions. The overall respondents were 197 (43.7\%). Anonymity was assured.

The questionnaire included questions about HBV vaccine status of the students; basic knowledge of hepatitis B vaccine and reasons for not receiving the vaccine was also assessed.

The data was analyzed by using statistical package for social sciences (SPSS) version 20 statistical package. Test of significance between proportions was assessed using Chisquare, and a $\mathrm{p}$ value of 0.05 or less. Ethical approval was insured.

\section{Results}

197 medical students were enrolled in this study, at KFU (years 1, 2 and 3) during the 2015 academic year. The response rate was $50 \%$. Their ages ranged from 19 to 21 years old. $44.2 \%(87 / 197)$ were male and $55.8(110 / 197)$ were female. $138(70.1 \%)$ students from year 1, $37(18.8 \%)$ from year 2 and $22(11.2 \%)$ from year 3, medical students, were included in this study.

$117(59.4 \%)$ of the participants had received the primary vaccination against $\mathrm{HBV}$ as infants. Up to $23(11.7 \%)$ of them did not take the primary vaccination. 57 (28.9\%) of these were not sure whether they received the vaccine or not. Figure 1 shows that the main reasons for not taking the primary vaccination were the lack of family education for 6 $(33.3 \%)$ of the participants and the unavailability of the vaccine for $7(38.9 \%)$ of them. $5(27 \%)$ didn't take the vaccine for other reasons.

After entering the college of medicine, only 141 of the 97 $(71.9 \%)$ participants had the post-vaccination test for hepatitis B surface antibody (HBs-Ab) and HBs-Ag to see if there is a need for another vaccine or booster doses. Table 1 shows that the result for HBs-Ab was positive in 44 participants $(22.3 \%)$ and 9 participants $(6.38 \%)$ did not remember. The remaining $88 \quad(62.9 \%)$ were negative. Unexpectedly, $9(5 \%)$ of the participants were found to be HBs-Ag positive. All other participants, 142 (68.5), were HBs-Ag negative.
Figure 2 showed that $156(84.8 \%)$ participants received the hepatitis B vaccine after entering the college of medicine, 28 $(15.2 \%)$ did not. Only $65(41.9 \%)$ of those who received the vaccine took the complete doses, and $88(56.8 \%)$ received only 1 or 2 doses. First year medical students were less vaccinated than third year students. $85 \%$ of the first year participants were vaccinated, whereas $90.5 \%$ of the third year participants received the vaccine, Table 2 . Besides, there was no significant statistical association between the results of the post-vaccination testing and taking the vaccine after entering the college.

When asked about the risk factors that the students did expose to, the answers varied between $17(8.9 \%)$ of the participants had contacted with known cases of HBV infection, 15 (7.7) have received blood transfusion, 74 (37.9) have been hospitalized and 17 (8.9) have a family history of HBV infection, Figure 3.

\section{Discussion}

This study was conducted among the $1 \mathrm{st}, 2^{\text {nd }}$ and $3^{\text {rd }}$ year medical students at KFU, Kingdom of Saudi Arabia, before starting their clinical training in hospitals. It aimed to find their immunization status against HBV and the factors behind poor response to the vaccination. Consequently it would be possible to determine the next step in regards to the need for vaccination, re-vaccination or booster dose.

Saudi Arabia has established the universal vaccination program against HBV for infants since 1990 (21). This vaccine was administrated to children at school entry in the period of 1990 to 1995 . The students who participated in this study were born in 1994 to 1996 (1). Therefore, all the students should have received the vaccine as infants. Unexpectedly, when asked if they had received the vaccine as infants up to $23(11.7 \%)$ of the students answered no, whereas $57(28.9 \%)$ were not sure if they had received the vaccine or not. Most of the students gave the lack of education in the family and the unavailability of the vaccine as reasons for not receiving the vaccine. This reflects the unawareness among medical students regarding vaccination strategies in KSA. It may also reflects a possible deficiency of the coverage of the Extended Program of Immunization (EPI) for infants in KSA, and that people in KSA may need more awareness about hepatitis B vaccine. However, this result is better than what was found in Taibah University where $52.4 \%$ of the students were unaware of whether they had received the vaccine or not, and $11.4 \%$ of the students were sure of not being vaccinated (22).

One important point that was found in this study; having no relationship between being positive $\mathrm{HBs}-\mathrm{Ab}$ in the postvaccination test and taking the vaccine. Even the students who have positive HBs-antibody took the vaccine again. It might be possible that the antibody titre had declined significantly with time. Surprisingly, $5 \%$ cases were having a positive HBs-Ag. These results should prompt caution in interpretation of positive $\mathrm{HBsAg}$ results; such as confirmatory testing, to ascertain true infection status and avoid the downstream consequences of false positives. 


\section{International Journal of Science and Research (IJSR) \\ ISSN (Online): 2319-7064}

Index Copernicus Value (2013): 6.14 $\mid$ Impact Factor (2015): 6.391

Generally, after entering the college of medicine about 156 (79.20\%) of the students were vaccinated. This compares with $18 \%$ observed in Cameron and $47.7 \%$ in Nigeria (16). Whereas $28(14.7 \%)$ of the medical students in KFU did not receive the vaccine before college, $82 \%$ in Cameron and $52.3 \%$ in Nigeria (16). It is considered to be high in comparison to only $22.3 \%$ of Indian medical students who have finished their doses and $77.7 \%$ who did not (23). Due to the higher percentage in KFU, the university recommended the entire student to be vaccinated, and the vaccine was available in the University's healthcare centre. However, the results have showed that only $67(43.2 \%)$ of those who received the vaccine took the complete doses, and $88(56.8 \%)$ received only 1 or 2 doses, and thus remain susceptible to the infection.

In this study HBV vaccination status among first year medical students is found to be less compared with second and third years. That shows the first year medical students have poor knowledge and lack of awareness about hepatitis $\mathrm{B}$, its routes of transmission, risk factors, and modes of preventions. In addition, it shows the risk factors of hepatitis B infection among medical students at KFU. Coming in contact with known cases and having a family history of $\mathrm{HBV}$ infection were risk factors that got the same percentage of $8.6 \%$ according to the medical students' responses. While receiving blood transfusion was less with $7.6 \%$. Though the majority of medical students thought they were at high risk of acquiring hepatitis B infection during hospitalization with $37.6 \%$.

This study is primarily limited by its small sample size and possible bias. There wasn't a good response from the students. However, the sample size could have been expanded by starting collecting the data earlier. This would have increased the time needed to find more participants. In addition, it would be better to conduct a serological test among students in the future.

Therefore, to achieve ultimate goal; it is recommended to apply more studies and surveillance for all future medical students and health care workers to ensure their protection against HBV infection. Besides, health promotion and awareness about the importance of vaccination, is to be more developed.

\section{Conclusion}

This study revealed high perception of medical students' risk for HBV infection. Only $84.8 \%$ students from first, second and third years are reported that they received one or more doses of hepatitis B vaccine. Knowledge of HBV, mode of transmission and hepatitis $\mathrm{B}$ vaccine was low among first year compared with second and third year medical students. It should be recommended from the university; organised orientation programmes and campaigns about hepatitis B infection prevention, control and vaccination. This will serve as a template in developing successful-orientation strategies among medical students at King Faisal University.

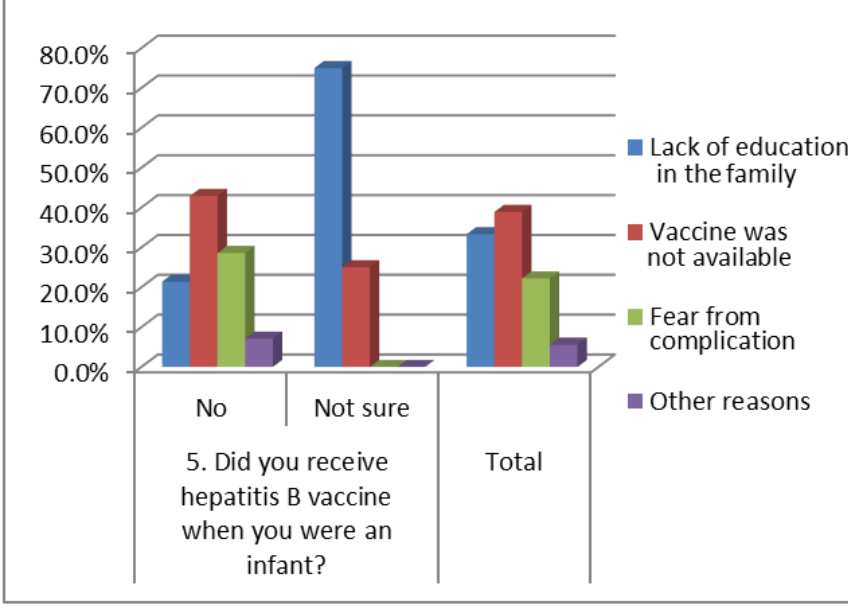

Figure 1: Reasons for not receiving the primary vaccination

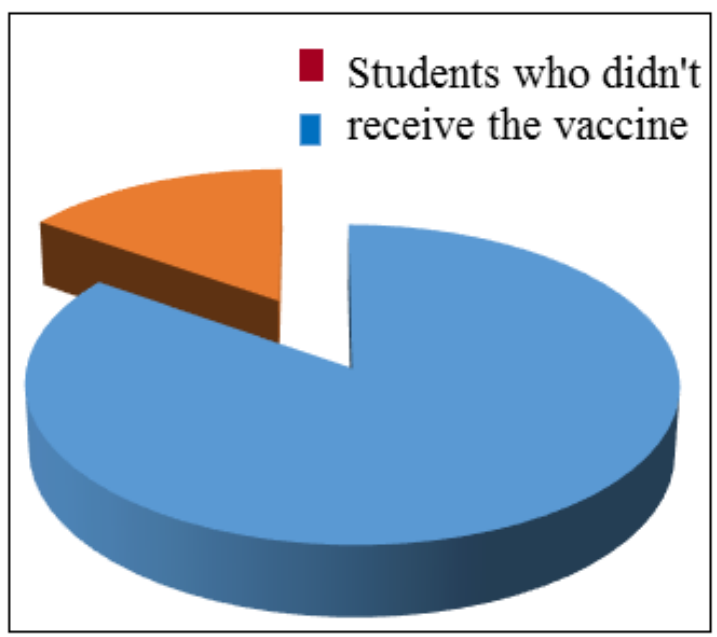

Figure 2: Vaccination after entering the college of medicine

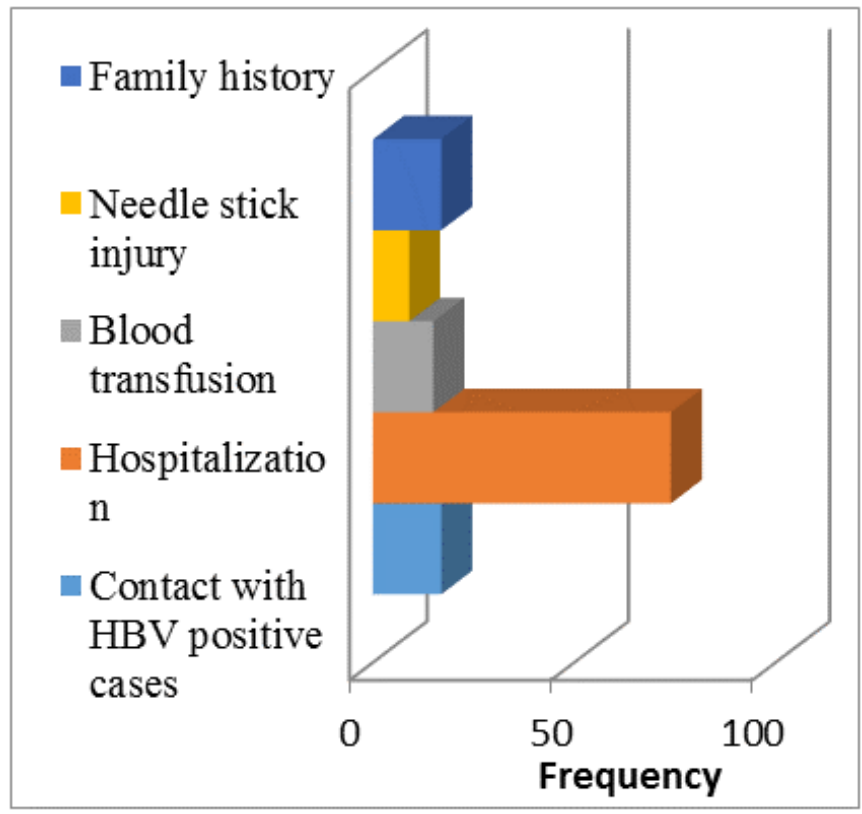

Figure 3: Hepatitis B risk factors among medical students. 


\section{International Journal of Science and Research (IJSR) \\ ISSN (Online): 2319-7064}

Index Copernicus Value (2013): 6.14 | Impact Factor (2015): 6.391

Table 1: Primary vaccination and the result of postvaccination testing

\begin{tabular}{|c|c|c|c|c|c|c|c|}
\hline & \multicolumn{4}{|c|}{ Post-vaccination testing } & \multicolumn{2}{|c|}{ Total } & \multirow{3}{*}{\begin{tabular}{|l|} 
P value \\
0.0001
\end{tabular}} \\
\hline & \multicolumn{2}{|c|}{$\begin{array}{c}\text { Received } \\
\text { primary } \\
\text { vaccination }\end{array}$} & \multicolumn{2}{|c|}{$\begin{array}{l}\text { Didn't receive } \\
\text { primary } \\
\text { vaccination }\end{array}$} & & & \\
\hline & No. & $\%$ & No. & $\%$ & No. & $\%$ & \\
\hline \multicolumn{8}{|l|}{ HBs-Ag } \\
\hline Positive & 7 & 5 & 2 & 5 & 9 & 5 & \\
\hline Negative & 114 & 80.9 & 10 & 70 & 124 & 68.5 & \\
\hline \multicolumn{8}{|l|}{ Anti-Hbs } \\
\hline Positive & 35 & 32.7 & 3 & 13.6 & 44 & 24.4 & \\
\hline Negative & 47 & 43.9 & 14 & 63.8 & 88 & 48.9 & \\
\hline
\end{tabular}

Table 2: The relation between receiving the vaccine and the students' batch

\begin{tabular}{|c|c|c|c|c|}
\hline \multirow{2}{*}{ Batch } & & \multicolumn{2}{|c|}{$\begin{array}{c}\text { Receiving the vaccine after } \\
\text { entering the college of } \\
\text { medicine }\end{array}$} & Total \\
\hline & & Yes & No & \\
\hline I & Count & 109 & 18 & 127 \\
\hline & \% within year : & $85.80 \%$ & $14.20 \%$ & $100.00 \%$ \\
\hline II & Count & 28 & 8 & 36 \\
\hline & \% within year : & $77.80 \%$ & $22.20 \%$ & $100.00 \%$ \\
\hline III & Count & 19 & 2 & 21 \\
\hline & \% within year : & $90.50 \%$ & $9.50 \%$ & $100.00 \%$ \\
\hline Total & Count & 156 & 28 & 184 \\
\hline & $\%$ within year : & $84.80 \%$ & $15.20 \%$ & $100.00 \%$ \\
\hline
\end{tabular}

\section{References}

[1] Murray P, Rosenthal K, Pfaller M. Medical Microbiology. $7^{\text {th }}$ Edition. 2013. Philadelphia: Elsevier Sauners; 2013.

[2] Shepard C, Simard E, Finelli L, Fiore, Bell B. Hepatitis B Virus Infection: Epidemiology and Vaccination. Epidemiol Rev (2006) 28 (1): 112-125.

[3] Ikeda K, Saitoh S, Suzuki Y, et al., "Disease progression and hepatocellular carcinogenesis in patients with chronic viral hepatitis: a prospective observation of 2215 patients," Journal of Hepatology, vol. 28, no. 6, pp. 930 938, 1998.

[4] McMahon B, Alward W, Hall D, et al., "Acute hepatitis $B$ virus infection: relation of age to the clinical expression of disease and subsequent development of the carrier state," Journal of Infectious Diseases, vol. 151, no. 4, pp. 599-603, 1985.

[5] Hou J, Liu Z, Gu F. Epidemiology and Prevention of Hepatitis B Virus Infection. Int J Med Sci. 2005; 2(1):50-57.

[6] Asif M, Raja W, Gorar Z. Hepatitis B vaccination coverage in medical students at a medical college of Mirpurkhas. J Pak Med Assoc. 2011 Jul; 61(7):680-2.

[7] Aljarbou A. The emergent concern of Hepatitis B with especial attention to Kingdom of Saudi Arabia. Int $\mathbf{J}$ health Sci (Qassim). 2013 NOV; 7(3):333-340.

[8] Teo E, Lok A. Epidemiology, transmission, and prevention of hepatitis B virus infection. 2014. [Updated: Dec 19, 2014; cited Feb 2015]. Available from:http://www.uptodate.com/contents/epidemiologytransmission-and-prevention-of-hepatitis-b-virusinfection
[9] Abdo A, Sanai F, Al-faleh F. Epidemiology of Vital Hepatitis in Saudi Arabia: Are we Off the Hook. Saudi J Gastroenterol. 2010 Nov-Dec; 18(6): 349-357.

[10] Kwon H, Lok AS. Hepatitis B therapy. Nature Reviews Gastroenterology \&Hepatology.8.5 (May 2011): p275.

[11]Bani I, mahofuz M, Gaffer EMA, ELhassan I, Yassin AO. Prevalence and risk factors of Hepatitis B Virus among Pregnant women in Jazan region-Kingdom of Saudi Arabia. Journal of Biology, Agriculture and Healthcare. 2013 Jan; 2:39-43.

[12] Beltrami E, Williams I, Chambertland M. Risk and Management of Blood-Borne Infections in Health Care Workers. Clin Microbial Rev.2000 Jul; 13(3): 385-407.

[13] Hadler S, Doto I, Maynard J, Smith J, Clark B, Moseley $\mathrm{J}$, et al. Occupational risk of hepatitis B infection in hospital workers. Infect Control 1985; 6:24-31.

[14] Okeke E, ladep N, Agabe E, Malu A. Hepatitis B Vaccination Status and Needle stick Injuries among Medical Student in a Nigerian University. Nijer J Med. 2008 Jul-Aug; 17(3)330-1.

[15] Sepkowitz K. Occupationally acquired infections in health care workers. Part II. Ann Intern Med. 1996 Dec $1 ; 125(11): 917-28$.

[16]Al-ajlan A. Prevalence of hepatitis B and C among students of health collages in Saudi Arabia. Eastmediterr health J. 2011Oct; 17(10): 759-62.

[17] Abbas Z, Jafri W, Shah S, Khokhar N, Zuberi S. PGS consensus statement on management of hepatitis B virus infection. 20013. J Pak Med Assoc. 2004; 54: 150-8.

[18] Aaby P, Aali B, Aandjaparida A, Aaqil M, Aarden L, Aaro L, et al. Introduction of hepatitis B vaccine into childhood immunization services. Switzerland: World Health Organization, Department of Vaccines and Biologicals 2001.

[19] AL-Ghamdi S, Fallatah H, Fetyani D, Al-Mughales J, Gelaidan A. Long-term efficacy of the hepatitis B vaccine in a high-risk group. J med virol. 2013 Sep; 85(9): 1518-22.

[20] Ven der sand M, Waigh P, Mendy M, Rayco-solon P, Hutt P, Fulfor T, et al. Long-term Protection against Carriage of Hepatitis B Virus after Infant Vaccination. J Infect Dis. 2006 Jun 1; 193(11): 1528-36.

[21] Madani T. Trend in incidence of hepatitis B virus infection during a decade of universal childhood hepatitis B vaccination in Saudi Arabia. Trans R Soc Trop Med Hyg.2007 Mar; 101(3):278-83. Epub 2006 Apr 5.

[22] Mosaad M, Al_Nozha O, Yammany H, Amer S. A survey of hepatitis B immune status of Taibah University medical. Journal of Taibah University Medical Science. 2014 Feb; 9(4): 301-306.

[23] Vinodhkumaradithyaa A, Srinivasan M, Uma A, Ananthalakshmi I, Thirumalaikolundusubramanian P, et al. Hepatitis B vaccination among medical students. Indian J Community Med. 2008 Jan; 33(1):67-8. doi: 10.4103/0970-0218.39 